\section{Manuel E. \\ Rodríguez \\ Vega $^{\star *}$}

\section{Pontificia}

\section{Universidad}

Católica de Chile, Chile

merodrig@uc.cl

Recibido: 17.04 .20

Aceptado: 03.09.21

\title{
Infracciones a garantías fundamentales y derecho al recurso en la jurisprudencia de la Corte Suprema
}

\section{Infractions of Fundamental Rights and the Right of Appeal at Supreme Court's Jurisprudence}

\begin{abstract}
Resumen: El presente trabajo examina la jurisprudencia de la Corte Suprema de Chile concerniente a la causal del recurso de nulidad de la letra a) del artículo 373 del Código Procesal Penal, estudio que evidencia que su interpretación sobre las materias que son de su competencia así como de los requisitos de admisibilidad y de fondo de dicha causal conducen a una desmesurada e injustificada limitación del derecho al recurso de los intervinientes en el proceso penal, y se proponen, entonces, lecturas alternativas que eviten dicho efecto.
\end{abstract}

Palabras clave: Corte Suprema; recurso de nulidad; derecho al recurso.

\begin{abstract}
This research examines the jurisprudence of the Supreme Court of Chile concerning the annulment appeal of Article 373, letter a), of the Code of Criminal Procedure, this study exposes that Court's interpretation about what matters are of its knowledge and about the requirements of that appeal, leads to an excessive and unjustified limitation on the right of appeal, we propose alternative interpretations that avoid that effect.
\end{abstract}

Keywords: Supreme Court; annulment appeal; right of appeal.

** Agradezco a quienes oficiaron como árbitros anónimos en el proceso de revisión de este trabajo por sus observaciones que hicieron posible subsanar errores de fondo y forma, y muy especialmente a la estudiante de Derecho, doña Amelia Muñoz Molina, por su muy valiosa colaboración en la redacción de la versión final de este texto. 
La reforma del procedimiento penal lograda en Chile en el año 2005 implicó sin duda un avance significativo en la recepción en nuestro ordenamiento adjetivo de los distintos derechos y garantías reconocidos en tratados internacionales, como la Convención Americana de Derechos Humanos y el Pacto Internacional de Derechos Civiles y Políticos, así como una esperada concreción de un derecho de contornos tan difusos como lo es el debido proceso consagrado en su Constitución Política.

Desde luego, tal recepción resultaría estéril si no se previeran igualmente mecanismos idóneos para evitar las vulneraciones a esos derechos y garantías o para conseguir que las mismas sean subsanadas, en su defecto. Entre esos últimos instrumentos reviste particular relevancia el recurso de nulidad y, en especial, su causal de la letra a) del artículo 373 del Código Procesal Penal (en adelante, CPP), cuyo conocimiento y decisión compete a la Corte Suprema, causal que procede cuando en cualquier etapa del procedimiento o en el pronunciamiento de la sentencia se hubieren infringido sustancialmente derechos o garantías asegurados por la Constitución o por los tratados internacionales ratificados por Chile que se encuentren vigentes ${ }^{1}$.

La singular trascendencia de esta herramienta deriva de su misma formulación, la que reconoce el superior estatus de ciertos derechos y garantías cuya esencia traza un límite que debe ser respetado durante todo el procedimiento por los agentes de persecución como por el órgano jurisdiccional, cuyos contornos son definidos o esbozados por la Corte Suprema, mediante la aplicación directa de la Constitución y los tratados internacionales en materia de derechos humanos, de manera de llenar los vacíos y sectores grises de la preceptiva legal, demarcando lo que forma o no parte de la garantía o derecho, desarrollando, por ende, una delimitación si se quiere externa, pero por otro lado fijando lo central o medular de la misma, esto es, un encuadre interno, igualmente relevante para la aplicación del principio de proporcionalidad al determinar el grado permitido de conmoción del derecho.

Todas estas orientaciones que la Corte aporta, por cierto, contribuyen a forjar paulatinamente estándares valiosos de respeto a los derechos y garantías de los imputados y terceros, sin embargo esta trascendente labor se ha visto frenada o moderada por decisiones del mismo tribunal expedidas al demarcar las materias que comprende su competencia, así como al controlar la satisfacción de los requisitos de admisibilidad y procedencia de la causal de nulidad en estudio, que redundan en una inmerecida restricción del derecho al recurso.

Recordemos que el derecho al recurso forma parte de la garantía a un justo y racional procedimiento reconocida en el artículo $19 \mathrm{~N}^{\circ} 3$, inciso $6^{\circ}$, de la Constitución, sin perjuicio de que se consagra directamente en los artículos 14.5 del Pacto Internacional de Derechos Civiles y Políticos y 8.2 letra h) de la Convención Americana de Derechos Humanos, que también integran el ordenamiento constitucional chileno por disposición del artículo 5 , inciso $2^{\circ}$ de la carta fundamental.

Sobre el derecho al recurso del condenado penalmente, la Corte Interamericana de Derechos Humanos ha declarado reiteradamente que el recurso debe ser accesible de manera que las formalidades requeridas para su admisión sean mínimas y no se erijan como un obstáculo para que cumpla con su fin de examinar y resolver los agravios sustentados por el recurrente; y, además, debe ser eficaz, de forma tal que, independientemente del régimen o sistema recursivo que adopten los Estados Partes y de la denominación que den al medio de impugnación de la sentencia condenatoria,

\footnotetext{
${ }^{1}$ Un sucinto esquema del recurso de nulidad presenta Orellana (2010, pp. 202-209), y sobre las características y finalidades de este arbitrio, v. Cerda (2010, pp. 805-807). Trata sus antecedentes históricos Núñez (2003, p. 333), Chahuán (2009, p. 348), Sandaña (2010, p. 228) y Mosquera y Maturana (2010, p. 325).
} 
constituya un instrumento adecuado para procurar la corrección de una sanción errónea². Asimismo, se ha señalado que el derecho al recurso, en cuanto derecho fundamental, supone interpretar las normas reguladoras de los recursos en el proceso penal del modo más favorable a su admisión y sustanciación, orientándose siempre hacia la efectividad del derecho, de modo que la mayor o menor severidad en la exigencia del requisito guarde proporción de medio a fin ${ }^{3}$.

Pero en el caso de la causal de la letra a) del artículo 373 del CPP, desmedidas restricciones en su ejercicio no solo implican la lesión del mismo derecho al recurso, sino que también perpetúan la infracción de los derechos fundamentales que se denuncia mediante éste y con el cual se busca su remedio o corrección, restricciones que, por tanto, igualmente se oponen al deber de la Corte de respetar y promoverlos, consagrado en el inciso $2^{\circ}$ del artículo 5 de la Constitución.

Por otra parte, las trabas procesales a la efectividad de este recurso, en tanto obstan la revisión de una sentencia condenatoria que priva o restringe la libertad ambulatoria del imputado, para considerarse respetuosas del principio de proporcionalidad, ${ }^{4}$ deben obedecer únicamente a razones o defectos graves que verdaderamente sean un obstáculo para un pronunciamiento de la Corte con el objeto de enmendar la infracción denunciada.

Entonces, la más efectiva y amplia vigencia del derecho al recurso, y del respeto y promoción de los derechos fundamentales cuya vulneración se delata mediante el arbitrio de nulidad, debe empujar una interpretación de las disposiciones adjetivas que lo norman, que permitan su operatividad como un recurso amplio y sin restricciones de acceso provenientes de un excesivo formalismo ${ }^{5}$.

Como se adelantó, la jurisprudencia de la Corte desatiende los derechos y principios antes referidos, dadas las barreras que ha ido levantando para el efectivo ejercicio del derecho al recurso, principalmente por parte del condenado penalmente, las que serán el objeto de análisis y crítica de este trabajo, y que pueden agruparse como limitaciones derivadas de: 1) la reducción de su competencia por la vía de encuadrar los hechos denunciados mediante la causal de la letra a) del artículo 373 del CPP en alguno de los motivos absolutos de nulidad del artículo 374 del CPP, 2) la adición de requisitos de admisibilidad a los controlables según los artículos 380 y 383 del CPP, 3) adelantar al examen de admisibilidad un pronunciamiento sobre el fondo de la controversia planteada en el recurso, 4) objetar la interposición conjunta de causales incompatibles, 5) declarar ciertas materias ajenas al recurso de nulidad, 6) restringir la legitimidad para deducir el recurso, 7) condicionar la suerte del recurso a la interposición de la causal de la letra e) del artículo 374 del CPP, y 8) una interpretación aritmética de los conceptos de sustancialidad de la infracción e influencia en lo dispositivo del fallo impugnado. Al finalizar se compendian las conclusiones que arroja este estudio.

\footnotetext{
2 v. "Herrera Ulloa vs. Costa Rica", de 2 de julio de 2004, y "Norín Catrimán y otros vs. Chile", de 29 de mayo de 2014. En cuanto al derecho al recurso y sus limitaciones en el proceso penal chileno, v. Duce y Riego (2007, p. 508-509), Riego (2007, p. 435), Del Río (2012, p. 254 y 2014, p. 17) y Moreno (2013, p. 211).

${ }^{3}$ Cortez (2006, pp. 25-26).

${ }^{4}$ Aldunate (2008, p. 264), explica que el principio de proporcionalidad examina la relación existente entre una medida de la autoridad, adoptada en el ámbito de sus facultades, gravosa para sus destinatarios, y la finalidad perseguida por esa medida. Esa medida, recuerdan Núñez, Beltrán y Santander (2019, p. 159), para adecuarse a este principio, debe satisfacer copulativamente tres requisitos: idoneidad, necesidad y proporcionalidad en sentido estricto.

${ }^{5}$ Como describen Horvitz y López (2008, p. 360) este recurso.
} 


\section{Limitaciones derivadas de la restricción de su competencia: reconducción de la infracción denunciada mediante la causal de la letra a) del artículo 373 del CPP a alguno de los motivos absolutos de nulidad del artículo 374 del CPP}

Una de las herramientas más recurrentes a que acude la Corte Suprema para circunscribir su conocimiento del arbitrio de nulidad, pero a la vez la menos estudiada, corresponde a la prevista en el artículo 383, inciso $3^{\circ}$, letra a), del CPP, que le permite no pronunciarse sobre su admisibilidad, sino que ordenar que sea remitido junto con sus antecedentes a la Corte de Apelaciones respectiva para que, si lo estima admisible, entre a conocerlo y fallarlo, si considera que de ser efectivos los hechos invocados como fundamento, serían constitutivos de alguna de las causales señaladas en el artículo 374 del CPP.

El examen de resoluciones en que se decide la reconducción refleja una utilización discrecional de esta vía, carente de lineamientos claros, que suele exceder los supuestos comprendidos en las causales aquereconduce, amparándose en la amplitud de los términos de algunas de éstas, en particular los de la letra c) del artículo 374 , con la consiguiente contracción de la competencia de la Corte para conocer de asuntos respecto de los cuales es el tribunal natural y el menoscabo del efecto uniformador para el respeto de garantías que pueda alcanzar una decisión favorable al recurrente.

Veamos algunos ejemplos.

Respecto de la reconducción a la letra b) del artículo
374 del CPP $^{6}$ que se decidió con fecha 8 de enero de 2020, Rol No 40.950-2019, la resolución señala que "los hechos que configuran la causal, que se han señalado como infracción de garantías constitucionales, en realidad constituye un reclamo propio de la causal del artículo 374 letra b) del Código Procesal Penal, en cuanto a que el juicio oral se reanudó sin la presencia del acusado", no obstante que esto último se regula en artículo 285 del CPP y no en las normas que trata dicho motivo de nulidad.

En cuanto al encuadre en la causal de la letra c) del artículo 374 del $\mathrm{CPP}^{7}$, dada la vaguedad de su texto constituye un asiduo camino para el reenvío, que suele abarcar infracciones que, en su formulación, parecen afectar sustancialmente el derecho al debido proceso, como ocurre en la sentencia de 30 de abril de 2020, Rol No 42.804-2020, en la que el recurrente protesta porque el tribunal de juicio oral en lo penal no accedió a la petición para reprogramar la audiencia, solicitud basada en "que uno de los testigos tiene domicilio en Perú, y ante el cierre de las fronteras le resultaba imposible prestar declaración"8.

Sobre la reconducción a la causal de la letra e) del artículo 374 del CPP9 , es corriente que la Corte encasille los reclamos por infracción a la presunción de inocencia,

\footnotetext{
6 "Cuando la audiencia del juicio oral hubiere tenido lugar en ausencia de alguna de las personas cuya presencia continuada exigen, bajo sanción de nulidad, los artículos 284 y 286".

7 "Cuando al defensor se le hubiere impedido ejercer las facultades que la ley le otorga".

${ }^{8}$ También sobre esta materia, sentencias de 30 de abril de 2020, Rol N 42.873-2020; 14 de julio de 2020, Rol N 78.852-2020; y 1 de septiembre de 2020, Rol No 95.056-2020.

9 "Cuando, en la sentencia, se hubiere omitido alguno de los requisitos previstos en el artículo 342, letras c),

d) $\circ$ e)".
} 
como atingentes al establecimiento de los hechos propios de la mencionada causal, como se aprecia en fallo de 20 de octubre de 2020, Rol No 124.395-2020, en el que se acusa la vulneración de "la garantía de la presunción de inocencia, el debido proceso, así como denuncia una errónea valoración de la prueba"10. Se observa igual resultado si se cuestiona la imparcialidad del tribunal a partir de la fundamentación del fallo, por ejemplo, en sentencia de 25 de noviembre de 2020, Rol $\mathrm{N}^{\circ} 134.015-2020^{11}$.

\section{Limitaciones por la vía de adicionar elementos sujetos al control de admisibilidad previsto en los artículos 380 y 383 del CPP}

En diversos pronunciamientos, la Corte ha declarado inadmisibles recursos de nulidad por motivos no contemplados expresamente entre aquellos que pueden ameritar esa sanción procesal conforme a los artículos 380 y 383 del CPP, no obstante el carácter estricto con el que deben interpretarse estas normas, no solo dada su misma naturaleza de sanción, sino por mandato del inciso segundo del artículo 5 del CPP en relación al imputado, toda vez que lo contrario conlleva restringir su derecho al recurso. Revisemos algunos de los extremos que ha escrutado y sancionado la Corte:

a) No señalamiento de la sustancialidad de la infracción, en sentencia de 9 de abril de 2020, Rol No 33.124-2020, lo que acarrearía "no cumplir las exigencias previstas en el artículo 378 del Código Procesal Penal”"12.

b) No indicación de la forma - conjunta o subsidiariamente- en que se interponen las causales de las letra a) y b) del artículo 373 del CPP, en fallo de 22 de octubre de 2019, Rol No 29.124-2019, señalando que con ello se incumple "la exigencia prevista en el artículo 378 del Código Procesal Penal".

c) Formulación de peticiones que "no resultan congruentes" con lacausal propuesta, en pronunciamiento de 19 de diciembre de 2019, Rol No 36.495-2019, al no solicitar la nulidad del juicio oral y de la sentencia pese a haber deducido la causal de la letra a) del artículo 373 del CPP.

En el primer supuesto, la Corte parece considerar que la explicación de la sustancialidad de la infracción está comprendida dentro de los fundamentos de derecho que debe contener el arbitrio, conclusión que se comparte, siempre que no se descarte que ese aspecto pueda desprenderse del mismo desarrollo que se lleve a cabo en el libelo.

En cuanto a los dos últimos asuntos, esto es, la indicación de la forma en que se interponen las causales y que se trate de peticiones congruentes con la causal

\footnotetext{
${ }^{10}$ Igual determinación en sentencias de 11 de febrero de 2020, Rol N².894-2020; 11 de febrero de 2020, Rol N 14.768-2020; 8 de abril de 2020, Rol N³0.154-2020; 1 de septiembre de 2020, Rol No 97.367-2020; y 1 de septiembre de 2020, Rol Nº 97.243-2020. Esos motivos, ahora, para rechazar la misma causal, en sentencia de 27 de febrero de 2020, Rol № 26.890-2019. Asimismo, si se cuestiona la integridad o continuidad de la cadena de custodia, la Corte asume que es una materia relativa a la valoración del objeto de la custodia quebrantada, como en fallo de 16 de abril de 2020, Rol № 14.771-2020.

${ }^{11}$ Algunos autores puntualizan que al revisar la Corte la vigencia de las garantías procesales que establecen exigencias respecto del modo en que los jueces deben apreciar la prueba, puede revisar el modo en que el tribunal del juicio ha apreciado la prueba y determinado los hechos que ha tenido por ciertos, y si estima que esa apreciación vulnera los estándares exigidos puede anular la decisión ordenando siempre en ese caso un nuevo juicio, así Riego (2007, p. 442), Duce y Riego (2007, pp. 517-518), Accatino (2009, p. 349) y Del Río (2014, p. 92).

${ }^{12}$ Además, sentencia de 15 de diciembre de 2020, Rol № 139.997-2020.
} 
deducida, la Corte parece también estimar que se trataría de exigencias inmanentes a la misma expresión de los fundamentos de derecho y de las peticiones concretas, respectivamente, disquisición que resulta atendible, pues la correcta expresión o formulación de las causales y de las peticiones es indispensable para la adecuada tramitación, conocimiento y decisión del recurso, empero, no puede desconocerse que los artículos 380 y 383 del CPP no prevén estas menciones como motivos para declarar la inadmisibilidad del arbitrio, por lo que, conjugando ambos aspectos, creemos que para precaver coartar injustificadamente el derecho al recurso respecto de una sentencia condenatoria en materia penal, y teniendo en vista de que se trata de omisiones o defectos formales fácilmente subsanables, lo proporcional sería otorgar un plazo acotado al recurrente para corregirlos antes de aplicar derechamente la sanción de inadmisibilidad, tal como se acostumbra en caso de errores en el ofrecimiento de la prueba conforme al artículo 359 del CPP.

\section{Limitaciones por la vía de adelantar al examen de admisibilidad un pronunciamiento sobre el fondo de la controversia planteada en el recurso}

Según sentencia de 17 de febrero de 2020, Rol No 15.031-2020, el recurso protesta porque el juzgado de garantía omitió escriturar y notificar la sentencia dictada en un procedimiento simplificado. La Corte declara inadmisible el arbitrio porque "al no ser efectivos los hechos constitutivos de la causal de nulidad interpuesta, el recurso carece (sic) de manifiesta falta de fundamentos".

Aquí, en realidad, el recurso no omite expresar razones, sino que las que presenta son erradas - conclusión que para ser alcanzada, como el mismo fallo admite, oficiosamente se procedió a "la revisión del sistema Siagj" - . Si bien puede parecer una decisión acertada para evitar sustanciar un recurso que evidentemente no tiene sustento fáctico, nos interesa resaltar que de extenderse esta forma de dirimir el fondo de lo planteado en los recursos ya en el examen de admisibilidad, en otros casos puede injustificadamente limitar el derecho de la parte afectada a explicar y acreditar los fundamentos del recurso en la respectiva audiencia.

\section{Limitaciones por la vía de objetar la interposición conjunta de causales incompatibles}

La Corte igualmente ha demostrado excesivo formalismo, similar al que evidencia en el tratamiento del recurso de casación regulado en el Código de Procedimiento Penal de 1906, frente a arbitrios que se basan en causales incompatibles formuladas conjuntamente, como en sentencia de 12 de febrero de 2020, Rol No 132.331-2020, donde el libelo rechazado se funda en los motivos de los artículos 373 letra a) y 374 letra e) del CPP, objetando por la primera el que se haya admitido una declaración por Zoom desde el hogar del testigo y, por la segunda, su valoración en el juicio, decidiendo la Corte que "en primer lugar se cuestiona la forma de incorporar la prueba testimonial, para luego cuestionar su apreciación, lo cual supone el reconocimiento de su validez. Se trata, entonces, de motivos de nulidad que, en la forma propuesta, resultan del todo contradictorios". 
Por cierto que en el fallo comentado se incurre en el defecto detectado, sin embargo, una interpretación que promueva la eficacia del derecho al recurso, debiera implicar al menos pronunciarse sobre la causal de competencia natural de la Corte, sin perjuicio de desestimar la otra por resultar incompatible con aquélla y no haberse deducido en subsidio, ya que de otra forma podrían dejarse sin sanción las infracciones de derechos fundamentales denunciadas, por meros defectos en su formulación en relación a otra causal, lo cual no parece armónico con el deber de respetar y promover esos derechos consagrado en el inciso $2^{\circ}$ del artículo 5 de la Constitución.

\section{Limitaciones por la vía de declarar ciertas materias ajenas al recurso de nulidad}

La Corte ha excluido de manera general ciertas materias como objeto de su conocimiento, incluso en sede de admisibilidad, con lo cual no sólo cercena su competencia por vía interpretativa, sino que priva absolutamente al recurrente de la posibilidad de demostrar en el caso particular la existencia de la infracción, con lo cual restringe nuevamente el derecho al recurso del agraviado. Revisemos algunos de esos ámbitos:

a) Desempeño del defensor en las audiencias de preparación del juicio oral y de juicio oral: en resolución de 14 de abril de 2020, Rol N³3.343-2020, se explicó que "la valoración de la actuación profesional no es un asunto sobre el cual deba pronunciarse este Tribunal y escapa además, a la naturaleza del recurso de nulidad, apareciendo del contenido del presente arbitrio, que el actual representante del acusado discrepa de la calidad que tuvo la defensa ofrecida por quien la condujo en las audiencias de preparación de juicio oral y de juicio oral, de modo que la pretensión invalidatoria no puede prosperar"13. Esta resolución anticipa una decisión sobre el fondo de lo planteado por el recurrente, ya que dirimir si se trata de una mera discrepancia sobre el desempeño del defensor anterior o una auténtica situación de indefensión requiere conocer los antecedentes de la causa y escuchar a las partes en la correspondiente audiencia. Esta línea jurisprudencial, además, genera el peligro de exceptuar de revisión y enmienda, procesos en los que objetivamente la actuación del letrado no supere el umbral mínimo que debe garantizar el Estado, riesgo que al menos se disipa si, en vez de declarar inadmisible este reclamo, se lo subsume en la causal del artículo 374 letra c) del CPP y se remite a la Corte de Apelaciones competente su conocimiento, tal como se llevó a cabo en otras oportunidades, como en fallo de 30 de abril de 2020, Rol No 42.873-2020.

b) No suspensión del procedimiento de conformidad con el artículo 458 del CPP: en sentencia de 15 de diciembre de 2020, Rol No 138.481-2020, la Corte declara inadmisible el recurso, señalando que "lo que se ataca en definitiva es que no se hubiese dado lugar a la petición de enajenación mental, desde que consta de los antecedentes, fue materia de discusión, debate y resolución en su oportunidad, e incluso fue objeto de pronunciamiento por la Corte de Apelación respectiva en su oportunidad y de esta Corte Suprema, pero aún de no haber sido revisado aquello, lo cierto es que los fundamentos en que descansa la causal principal de nulidad interpuesta por la defensa, exceden el ámbito del recurso de nulidad". El que esa cuestión haya sido objeto de debate y resolución anteriormente, no puede erigirse sin más como óbice para la admisibilidad de este arbitrio, menos aún si su reclamo previo es precisamente

${ }^{13}$ En el mismo sentido, sentencia de 4 de febrero de 2020, Rol N².892-2020. 
una exigencia del artículo 377 del CPP. Dejando de lado esto, sí resultará procedente la causal del artículo 373 letra a) en el evento de que efectivamente el juzgado de garantía haya cometido una infracción sustancial a derechos fundamentales durante el procedimiento llevado adelante para establecer la imputabilidad, por ejemplo, zanjar ese punto sin requerir previamente un informe al Servicio Médico Legal o hacerlo fuera de audiencia sin escuchar a los intervinientes, desde que el resultado de esa decisión en definitiva puede provocar someter al imputado a un procedimiento ordinario que no prevé los resguardos procesales adecuados que amerita esa condición.

c) Infracción de garantías fundamentales al interpretar el contenido de un tipo penal: en sentencia de 14 de febrero de 2020, Rol No 15.033-2020, en la que el recurso denuncia "la infracción a la dignidad personal, libertad y autonomía, así como a la garantía al debido proceso y a otras que señala en su recurso, toda vez, que (...) estos hechos de acuerdo a los antecedentes que obran en el proceso sería una conducta de auto cultivo", se decide "que lo alegado por el impugnante dice relación con la errónea aplicación del derecho, cuestión que, a pesar que se invocan garantías constitucionales que se dicen vulneradas, aquello constituye más bien la causal de nulidad del literal b) del artículo 373 del Código Procesal Penal”14. Esta decisión supone atenuar el rol primordial de la Corte para definir el influjo de los derechos fundamentales, acotándolo únicamente a su interacción con las normas adjetivas y no así con las sustantivas, no obstante la relevancia de esos derechos en la exégesis de los tipos penales y la determinación de la conducta penalmente prohibida.

\section{Limitaciones por la vía de restringir la legitimidad para deducir el recurso}

La Corte, por las razones y en los supuestos que se citarán a continuación, ha impedido el ejercicio del derecho al recurso del imputado y la víctima, supeditando la admisibilidad y procedencia del arbitrio a condiciones desarrolladas en el ámbito comparado que no sintonizan del todo con el ordenamiento procesal chileno, en la primera hipótesis analizada y, en la segunda, oponiéndose al texto expreso de la ley.

6.1. El recurso puede interponerse únicamente por el afectado directamente por la infracción de garantías

Ha sido uniforme la jurisprudencia del Máximo Tribunal en señalar que el arbitrio de nulidad en el que se protesta por la valoración de prueba obtenida ilícitamente, debe deducirse por el agraviado inmediatamente por la infracción de garantías de la que proviene esa ilicitud, como se decidió en sentencia de 22 de noviembre de 2016, Rol No 73.836-2016, declarando al rechazar el recurso que "el eventual vicio que se reclama afectó a una persona distinta a la imputada, quien no formuló cuestionamiento alguno a la actuación sino que, muy por el contrario, prestó declaración en el juicio oral admitiendo la transacción ilícita"15. Incluso ha propugnado esta tesis al decidir la inadmisibilidad del pleito, por ejemplo, en sentencia de 20 de octubre de 2020, Rol No 122.149-

\footnotetext{
${ }_{14}$ De igual forma, en fallos de 23 de diciembre de 2019, Rol N 36.736-2019 y 16 de septiembre de 2020, Rol N 104.407-2020, este último en el que se impugna el rechazo a declarar la media prescripción de la acción penal. En casos similares, la Corte sí ha aceptado la admisibilidad de la causal de la letra a) del artículo 373, como en sentencia de 4 de junio de 2015, Rol N 4.949-2015, pero al resolverla se indica que lo alegado se acomoda más bien a la de la letra b) del artículo 373, interpuesta en subsidio, que en definitiva acoge.

${ }^{15}$ El mismo derrotero en sentencias de 24 de julio de 2017, Rol № 24.860-2017; 8 de enero de 2018, Rol № 42.684-2017; 3 de junio de 2019, Rol No 9.140-2019; 27 de enero de 2020, Rol №33.699-2019; y 8 de abril de 2021, Rol № 14.317-2021.
} 
2020, la que expresa que "el reclamo se funda en la afectación de garantías de terceras personas, a lo que cabe agregar que no se ha demostrado que los afectados por las actuaciones que el recurrente considera viciadas no han hecho uso del sistema recursivo, lo que resta fuerza a los argumentos en los que sustenta su reclamo, de tal forma que sus alegaciones carecen del agravio necesario".

Esta línea jurisprudencial supone aceptar que antecedentes que, indiscutiblemente, sean obtenidos mediante una actuación que afecta los derechos fundamentales de una persona distinta al imputado, pueden servir de fundamento para la decisión condenatoria y para la consiguiente restricción de libertad $^{16}$.

De la mano de lo propuesto por diversos autores ${ }^{17}$, sostenemos que el acusado está legitimado para recurrir de nulidad contra la sentencia que se funda en prueba ilícitamente obtenida de terceros, por las siguientes razones:

a) El criterio que se examina no halla asidero en el texto del artículo 373 letra a) del CPP ni en los artículos 380 y 383 como motivo de inadmisibilidad, y respecto a la alusión a la falta de "agravio" efectuada en el último fallo arriba citado, que nos remite al artículo 352 del CPP, cabe precisar que dicho precepto se refiere al agravio causado por la resolución judicial, que en el caso del imputado proviene de la imposición de la condena, y no al agravio inmediato ocasionado por la actuación policial que vulnera un derecho fundamental sobre el que se pronuncian los fallos comentados.

b) De otra forma se contraviene lo expresado en innumerables sentencias de la misma Corte ${ }^{18}$, en las que la ineficacia de la prueba ilícita se construye en la preservación de la integridad judicial, conforme a la cual dicha atención en el titular del derecho vulnerado carecería de asidero pues, en definitiva, en cualquier caso el fallo se cimenta sobre la base de una infracción a garantías fundamentales que no puede ser aceptada ${ }^{19}$.

c) Si la Corte estimara que el fundamento de la ineficacia probatoria es la disuasión (deterrence) de los agentes de persecución en la obtención de evidencia por medios ilícitos, una aplicación más amplia de la exclusión de prueba en favor de estos terceros tendrá igualmente un efecto mayor en la reducción de la frecuencia de este tipo de infracciones.

d) Si bien el derecho a la privacidad o libertad personal afectado puede corresponder a un tercero, la utilización en el juicio de la prueba derivada de esa ilicitud constituirá una infracción directa al debido proceso del propio imputado 20 .

e) Además, con la postura de la Corte, pierden efectividad todas las normas que regulan las diligencias que privan, restringen o perturban derechos cuando de éstos el titular no es el imputado sino un tercero, o lo es un coimputado que no recurre de nulidad, con la consiguiente desprotección que acarrea, pues desincentiva el apego

\footnotetext{
${ }^{16}$ Así la Corte sigue la doctrina del standing de su par estadounidense aplicada en Rakas v. Illinois, 439 U.S. 128 (1978). En Alemania se llega a similar conclusión, pero como resultado de la fuerte orientación hacia las reglas de la casación en el tratamiento de las prohibiciones de valoración, de las que se desprende que sólo podrían alegarlas aquellos que han sufrido agravio por su infracción, v. Hernández (2005, p. 41).

17 Hernández (2005, p. 70) y Horvitz y López (2008, pp. 213-214 y 414).

18 Entre muchos otros, v. fallos de 23 de mayo de 2016, Rol No21.430-2016; 20 de abril de 2017, Rol № 39.475-2016; 6 de diciembre de 2018, Rol No 26.422-2018; 7 de marzo de 2019, Rol No 2.224-2019; y 25 de junio de 2021, Rol No 25.386-2021.

19 Según el criterio de la integridad judicial, como comentan Horvitz y López (2008, p. 183), lo que justifica la regla de exclusión es la convicción de que en la persecución penal no pueden admitirse métodos que ofenden el sentido comunitario de juego limpio y decencia. Sobre este punto, también Hernández (2005, p. 14) y Zapata (2004, pp. 46-55) quien fundamenta la regla de exclusión en la supremacía constitucional y la vinculación directa de la Constitución, así como en la garantía del debido proceso.

${ }^{20}$ En fallo de 25 de mayo de 2010, Rol No 1.741-2010, se enseña que la ilicitud de la prueba forma parte del contenido nuclear del derecho a la presunción de inocencia, concepto fuertemente ligado al debido proceso.
} 
por parte de los agentes de persecución al procedimiento debido en esos supuestos.

f) En definitiva, seguir la doctrina en comento impulsaría el uso en juicio de evidencia que los agentes de persecución han obtenido, incluso deliberadamente, violando los derechos fundamentales de quienes no son imputados en la investigación.

6.2. El recurso del Ministerio Público y del querellante no puede descansar en la infracción de garantías fundamentales

Si durante el procedimiento se ha afectado el derecho al debido proceso de un interviniente distinto al imputado y su defensa, como si se impide al fiscal incorporar al juicio su prueba enunciada en el auto de apertura, el recurso de nulidad deducido por el fiscal o el querellante que impugne la sentencia absolutoria resultante de dicha afectación será rechazado por la Corte conforme a su jurisprudencia constante de la última época, por ejemplo, sentencia de 2 de julio de 2019, Rol No 12.003-2019 en la que declara que la causal de la letra a) del artículo 373 CPP "busca remediar las infracciones sustanciales a derechos y garantías fundamentales del imputado, esto es, de quien se enfrenta a la persecución de los órganos del Estado encargados de ello, persecución mediante la que se pretende la imposición de una sanción penal en su contra y, por consiguiente, se expone el perseguido, de no enmendarse esas infracciones, a una privación o restricción de su libertad personal y otros derechos, carente de legitimidad"21.

Este discernimiento, aun cuando plausible en lo tocante a las protestas del fiscal, ya que atendidas las razones que expone la Corte, pueden limitarse las resoluciones judiciales contra las que ese interviniente tiene facultad para recurrir según el artículo 352 del CPP, no parece igualmente viable en lo alusivo a la víctima, toda vez que se opone frontalmente el artículo 109 letra f) del CPP, que le reconoce la facultad de impugnar la sentencia absolutoria, incluso "cuando no hubiere intervenido en el procedimiento", lo que revela el claro propósito del legislador de conferirle los medios para insistir en el ejercicio de la acción penal que el artículo 83 de la Constitución le reconoce.

\footnotetext{
${ }^{21}$ También, fallos de 31 de enero de 2020, Rol № 250-2020; 17 de marzo de 2020, Rol № 24.696-2020; y 9 de abril de 2020, Rol Nº $30.166-2020$. Este criterio incluso ha servido de apoyo para la declaración de inadmisibilidad, v. fallos de 31 de enero de 2020 , Rol N ${ }^{\circ}$ 1.561-2020 y 30 de abril de 2020, Rol No 42.778-2020, los que incrementan los supuestos ya analizados en el apartado 2 at supra en que la Corte adiciona requisitos de admisibilidad no previstos en la ley. Repasan esta jurisprudencia, Cerda (2010, p. 814), Núñez (2012, pp. 244-246) y Blanco (2011, p. 541-542). La doctrina se halla dividida en este punto. Niegan la comentada legitimidad: Maier (2004, pp. 708-709), Hernández (2005, p. 65), Rieutord (2007, p. 33), Duce y Riego (2007, p. 523) y Horvitz y López (2008, pp. 360-361 y 410). Mientras que Tavolari (2005, pp. 268-269), Cortez (2006, p. 75), Mosquera y Maturana (2010, p. 325) y Del Río (2012, p. 266), admiten esta legitimación.
} 


\section{Limitaciones por la vía de condicionar la suerte del recurso a la formulación de la causal de la letra e) del artículo 374 del CPP}

La Corte ha aceptado la audiencia de juicio oral como instancia oportuna para discutir y probar el modo ilícito en que se obtuvo la prueba incluida en el auto de apertura, ${ }^{22}$ no obstante el pronunciamiento anterior del juzgado de garantía que lo descarta y, por ende, ha admitido conocer recursos de nulidad en los que precisamente se protesta por la valoración de prueba que se tacha de ilegítima por el recurrente ${ }^{23}$. Es más, alegar tal ilicitud en aquel estadio del proceso parece ser una exigencia de admisibilidad del recurso de nulidad conforme al artículo 377 del CPP, que requiere haber "reclamado oportunamente del vicio o defecto"24.

Pues bien, puede el defensor discrepar de la dinámica de hechos que el tribunal establece como aquella en la que se habría obtenido la prueba y a base de la que desestima la petición para declarar la ilicitud de su obtención. Verbigracia, el defensor postula que el imputado no manipulaba el arma de fuego que se encuentra después tirada en la cercanía, cuando es avistado por los policías, relato en que se afirma su alegación de que dichos agentes llevan a cabo un control de identidad sin el indicio habilitante que requiere el artículo 85 del CPP, mientras que la sentencia establece lo opuesto - que sí manipulaba el arma al ser divisado-. En episodios como éste, habitualmente en el libelo en que se formula el recurso de nulidad fundado en la causal de la letra a) del artículo 373 del CPP, conforme con el artículo 359 del mismo código, se ofrecen como medios de prueba para acreditar los supuestos fácticos que componen la causal invocada, el registro de audio de las declaraciones prestadas en el juicio oral por los policías actuantes, o se alude a las transcripciones que de ellas se efectúa en la sentencia que dicta el tribunal de la instancia, o al contenido del parte policial, buscando con ello que la Corte, para dirimir la licitud del acto cuestionado, tenga por cierto un escenario fáctico diverso al que fijaron los magistrados del grado.

Al respecto, la Corte reiteradamente ha rehusado valorar esos elementos probatorios al conocer un recurso de nulidad y, por ende, se ha excusado de establecer los sucesos de una manera diferente a aquella que sentaron los magistrados, en síntesis, porque desconocerlos y sustituirlos por otros significaría abrir una nueva ventana para discutir lo ya concluido por el tribunal a $q u o^{25}$. Ha señalado la Corte, además, en sentencia de 23 de diciembre de 2019, Rol No 29.032-2019, que al "no haber acusado el recurrente que en la sentencia se

\footnotetext{
22 Ver sentencias de 30 de enero de 2018, Rol N 44.457-2017; 19 de diciembre de 2019, Rol N²0.397-2019; 19 de diciembre de 2019, Rol No 20.424-2019; y 8 de abril de 2021, Rol No 14.317-2020. Aisladamente, en sentido opuesto, la sentencia de 16 de junio de 2021 , Rol No 17.299-2021, que declaró que la audiencia de preparación de juicio oral es la instancia en que debe producirse el debate acerca de la prueba que habrá de rendirse en el juicio oral, pudiendo en esta oportunidad solicitarse su exclusión, agregando que no puede abrirse debate sobre la prueba admitida por el juzgado de garantía en el auto de apertura de juicio oral, ya que dicha resolución, al encontrarse firme o ejecutoriada, ha adquirido autoridad de cosa juzgada.

${ }^{23}$ La competencia y facultad del tribunal de juicio oral en lo penal para excluir de la valoración los medios de prueba que estime ilícitos, es avalada por Hernández (2005, p. 90); Romero (2007, p. 25); y Awad, Contreras y Schürmann (2013, p. 416). En sentido opuesto, Tavolari (2003, pp. 151-160), Horvitz y López (2008, pp.197-204) y Cortés-Monroy (2018, pp. 661-692).

${ }^{24}$ Así se decidió en fallo de 9 de junio de 2020, Rol N 62.816-2020.

${ }^{25}$ v. sentencias de 26 marzo 2018, Rol № 2.519-2018; 26 de junio de 2019, Rol № 12.166-2019; y 22 de enero de 2020, Rol N²9.1602019. Concuerdan con reservar el establecimiento de los hechos a los tribunales de las instancias, Jiménez (2003, p. 277), Tavolari (2005, p. 211), Carocca (2009, p. 185) y citando jurisprudencia en el mismo sentido, Blanco (2011, p. 525) y Núñez (2012, p. 243). Críticos frente a dichas limitaciones basadas en la oralidad e inmediación, son Cortez (2006, p. 319), Accatino (2009, p. 355), Del Río (2012, p. 279) y Palomo y Lorca (2018, p. 37).
} 
hubiese incurrido en el defecto que sanciona con nulidad el artículo 374 letra e) del Código Procesal Penal, (...) no resulta posible discurrir en base a hechos distintos de los asentados en el fallo"26.

Si bien adherimos a la preocupación de la Corte expresada en el primer fallo citado, la solución que entrega en la segunda sentencia mencionada es aparente. En efecto, en ésta pareciera afirmar que, de haberse interpuesto también la causal de la letra e) del artículo 374, la Corte se encontraría en buen pie, entonces, para modificar los hechos descritos por el tribunal a quo sobre la forma en que se obtuvo la prueba para, a renglón seguido, sobre la base de este nuevo relato dar lugar a la causal de la letra a) del artículo 373, lo que resulta equivocado. En efecto, si se deduce la causal de la letra e) del artículo 374 del CPP para cuestionar la forma en que se establecen los hechos que constituyen la infracción de garantías fundamentales, pueden presentarse los siguientes escenarios, ninguno de los cuales permite salvar el escollo en comento: primero, si esa causal se plantea en subsidio de la letra a) del artículo 373, aquélla no va a ser tenida en cuenta al resolverse ésta, sea que se acoja o rechace; segundo, si la causal principal es la de la letra e) del artículo 374, de darse lugar a ésta, la Corte no se pronunciará de la letra a) del artículo 373; y si se deducen conjuntamente las causales mencionadas, la Corte podría estimarlas incompatibles y rechazarlas ambas, como ya se examinó en la sección 4 at supra o, de acogerse la causal de la letra e) del artículo 374, la Corte nada más podría ordenar repetir el juicio, pero no fijar los hechos de manera diversa y basada en éstos dar lugar a la causal de la letra a) del artículo 373.
Pareciera el único remedio a este atolladero que el recurrente funde su arbitrio de nulidad en la causal de la letra e) del artículo 374, buscando con ello primero invalidar el juicio y la sentencia por un defecto de ésta en la determinación de los hechos referidos al modo en que se obtiene la prueba objetada, de manera que, en el eventual segundo juicio, una vez fijados correctamente los hechos, el tribunal sí tenga por configurada la infracción de derechos. Sin embargo, esta alternativa no está exenta de reparos pues, si en el segundo juicio los sentenciadores vuelven a fijar los mismos hechos del primer juicio anulado o no obstante su establecimiento del modo que busca la defensa concluyen que ello no importa una infracción de derechos fundamentales, traerá como corolario la imposibilidad de presentar un nuevo recurso de nulidad, como prescribe el artículo 387 del CPP y, por consiguiente, al cabo de este rodeo se llegará al mismo punto muerto.

Como se observa, las implicancias de las resoluciones en análisis, conjugadas con la preceptiva aplicable -artículo 387 del CPP - limitan severamente las posibilidades de plantear, discutir y probar una infracción de derechos fundamentales ante la Corte, con lo que quedan, entonces, confinados los casos en que podría acoger este recurso de nulidad a aquellos en que el impugnante no discute los hechos que tiene por ciertos el tribunal a quo, sino únicamente si éstos permiten calificar de ilícita la forma en que se obtuvo la prueba cuestionada.

\footnotetext{
${ }^{26}$ De igual modo en fallos de 23 de diciembre de 2019, Rol № 29.032-2019; 13 de marzo de 2020, Rol № 14.733-2020; 19 de marzo de 2020, Rol No 15.028-2020; y 26 de marzo de 2020, Rol No 14.773-2020.
} 


\section{Limitaciones por la vía de una interpretación aritmética de los conceptos de sustancialidad de la infracción e influencia en lo dispositivo del fallo impugnado}

La Corte, en diversos fallos ${ }^{27}$, ya sea al tratar el extremo de la sustancialidad de la infracción o su influencia en lo dispositivo del fallo -requisito que también estima pertinente a la causal de la letra a) del artículo $373-{ }^{28}$, suele dirimir su concurrencia atendiendo si la prueba rendida en el juicio que no proviene de aquella actuación a la que el impugnante endilga ilegalidad resultaba o no igualmente suficiente para arribar a la decisión condenatoria, como lo hizo en sentencia de 11 de septiembre de 2020, Rol № 90.633-2020: "se ha dicho que la infracción producida a los intereses del interviniente debe ser sustancial, (...) situación que no se ha advertido en la especie, toda vez que, aun prescindiéndose de los testimonios de aquellos testigos que no depusieron en sede fiscal, los sentenciadores habrían estado en condiciones de arribar a la misma conclusión con la restante prueba de cargo", mientras que en fallo de 16 de noviembre de 2020, Rol No 119.102-2020, se concluye que "aun cuando se estimara que el imputado declaró ante los policías sin las exigencias legales, las demás pruebas de cargo eran suficientes para establecer su autoría", por lo que la infracción alegada carecería de la trascendencia que demanda el artículo 375 del CPP29.

Tales disquisiciones de la Corte conducen nuevamente a una infundada limitación del derecho al recurso, desde que el ejercicio que implícitamente efectúa supone necesariamente sustituir el lugar de los jueces de la instancia y, en cierta forma, volver a valorar los antecedentes probatorios incorporados en el juicio, de manera de sopesar si aquellos no afectados por la ilegalidad son bastantes todavía para mantener la convicción condenatoria, operación que, desde luego, se realiza conforme a la apreciación personal de los jueces del tribunal de nulidad. Por otra parte, lo valorado para estos efectos ni siquiera será la misma prueba rendida en el juicio, sino el mero extracto, resumen o nota que de ella se ha hecho en el fallo impugnado, compendio que generalmente se confeccionará buscando destacar aquellos aspectos de la prueba que sirvieron a los sentenciadores para respaldar su decisión condenatoria, por lo que el conocimiento de la Corte es altamente

\footnotetext{
${ }^{27}$ Exponen parte de esta jurisprudencia, Pfeffer (2010, pp. 247-248), Blanco (2011, pp. 529 y 564) y, además, su análisis, en Rodríguez (2020, p. 69).

${ }^{28}$ Entre los autores, Cortez (2006, p. 147) menciona tres supuestos de limitaciones al recurso de nulidad, que en realidad corresponden a un mismo y único motivo: la trascendencia, la falta de influencia en lo dispositivo y la falta de perjuicio. Para Rieutord (2007, p. 4243), una infracción sustancial de garantías en el juicio no necesariamente podrá verse reflejada en la sentencia respectiva, sin embargo, puntualiza que el principio de trascendencia está recogido en esta causal bajo el concepto de sustancialidad, la que estaría dada por las consecuencias efectivas y constatables que la infracción en cuestión produjo al recurrente; Horvitz y López (2008, pp. 414-415) sostienen que el requisito de una "infracción sustancial" pretende sustituir el de "influencia en la parte dispositiva de la sentencia" que el artículo 375 contempla para la causal de la letra b) del artículo 373, aunque igualmente consideran aplicable este último a la causal de la letra a) del artículo 373 por la exigencia general de agravio en todo recurso y de perjuicio aplicable a toda nulidad; Cerda (2010, p. 811 y 821), por su parte, indica que el recurrente debe haber sufrido un perjuicio consistente en la privación de algún beneficio o facultad procesal dentro del procedimiento, lo que se desprende de lo señalado en el artículo 375 del CPP, agregando que los vicios que autorizan el recurso de nulidad deben estar presentes en la parte resolutiva de la sentencia o al menos incidir en ella, mientras, Moreno (2013, p. 215) postula que de la exigencia de sustancialidad de la infracción se desprende la de un perjuicio efectivo.

${ }^{29}$ Bajo similares argumentos, v. sentencias de 21 de febrero de 2017, Rol No 100.710-2016; 7 de marzo de 2018, Rol N 1.127-2018; 3 de junio de 2019, Rol No 9.140-2019; 30 de septiembre de 2019, Rol No 23.136-2019; 28 de octubre de 2019, Rol N²1.413-2019; 29 de mayo de 2020, Rol N 42.776-2020; 11 de septiembre de 2020, Rol N 90.633-2020; y 7 de octubre de 2020, Rol N $97.242-2020$.
} 
fragmentario y de baja calidad. Además, el razonamiento en examen empuja a soluciones de corte aritmético como afirmar, por ejemplo, que de prescindirse de un testimonio, todavía se contaría con otros dos testigos que entregaron el mismo relato, dejando de lado la relevancia que individualmente le hayan otorgado los jueces a cada deposición según lo apreciado directamente en el examen y contraexamen, como si el testimonio viciado es aportado por un testigo presencial mientras que los que se mantienen corresponden a testigos de oídas de la víctima. Asimismo, este criterio importaría dejar sin sanción un gran número de infracciones de garantías fundamentales cometidas en la obtención de evidencia, las que siempre se diluirían frente a alguna otra prueba de cargo válidamente obtenida a la que la Corte pudiera echar mano para estos efectos ${ }^{30}$.

La línea de razonamiento que propugnamos se siguió por la misma Corte en sentencia de 9 de enero de 2018, Rol N ${ }^{\circ}$ 28.305-2018 al decidir que la omisión imputable al juzgado de garantía de no incluir en el auto de apertura los testigos ofrecidos por la defensa no puede alzarse como impedimento para que declaren en el juicio oral y, al no resolverlo de ese modo, el tribunal de juicio oral en lo penal vulnera el derecho al debido proceso del imputado, ello, sin detenerse la Corte en la relevancia de esos testigos para zanjar si sus declaraciones habrían cambiado lo decidido por el a quo. Señala este fallo que la "sustancialidad no dice relación con lo resolutivo del fallo, ya que ello en la especie obligaría a ponderar prueba para verificar una eventual y diversa conclusión fáctica, sino con la entidad o dimensión de la vulneración de que trate. La situación es similar a los motivos absolutos: no se precisa demostrar perjuicio -porque se le presume cuando se trata de esta clase de infracciones- ni incidencia en lo resolutivo, pero debe constatarse que se trata de una infracción relevante de los derechos o garantías establecidos en la Constitución y los tratados internacionales"31.

\footnotetext{
${ }^{30}$ Razones desarrolladas en Rodríguez (2020, p. 71). Como ahí se dijo, el criterio de la Corte solo resultaría admisible en casos en que sea palmario que los antecedentes derivados de la actuación ilegal en caso alguno incidieron en la decisión impugnada o que su contribución fue extremadamente marginal frente al cúmulo de probanzas de cargo respecto del mismo asunto, por ejemplo, la declaración de la cónyuge a la que no se advierte de la facultad de no declarar según el artículo 302 del CPP, pero que solo refirió que no estuvo presente cuando ocurrieron los hechos y nada sabe sobre los mismos.

${ }_{31}$ De la misma manera, en fallos de 7 de marzo de 2019, Rol № 2.224-2019 y de 23 de octubre de 2020, Rol № 112.393-2020. Por otra parte, la Corte, correctamente, en general no alude a $-y$, por ende, no aplica - la definición y presunción de perjuicio de las normas relativas a la nulidad procesal de los artículos 159 y siguientes del CPP para la determinación de la sustancialidad de la infracción que demanda la causal de nulidad en estudio, desde que no parecen compatibles los artículos 160 y 373 letra a) porque el primero presume perjuicio en toda infracción que impida el "pleno" ejercicio de los derechos, es decir, ante cualquier impedimento menor operaría esa presunción, lo que es contrario a la exigencia de sustancialidad del segundo. Así lo ha resuelto en veredicto de 10 de octubre de 2018 , Rol N 20.749-2018. Horvitz y López (2008, pp. 415-416, n. 133), si bien estiman aprovechable el concepto de perjuicio del artículo 159 del CPP para definir la misma exigencia de la causal de nulidad de la letra a) del artículo 373 del CPP, descartan que sea suficiente para determinar el concepto de infracción sustancial, ya que ella deja de lado el problema de la entidad de la infracción con respecto al derecho comprometido. Sin embargo, la Corte ha tenido pronunciamientos en sentido contrario, como el fallo de 11 de noviembre de 2019 , Rol $N^{\circ}$ 27.768-2019. Se valen de la presunción del artículo 160 CPP para establecer el perjuicio que requiere el recurso de nulidad, Mosquera y Maturana (2010, p. 338).
} 


\section{Conclusiones}

EICPP concentra en la CorteSupremala competenciapara conocer el recurso de nulidad por infracciones sustanciales a derechos o garantías asegurados por la Constitución o por los tratados internacionales ratificados por Chile que se encuentren vigentes, correspondiente a la causal prevista en el artículo 373 letra a) de dicho texto, con lo que toca a este tribunal la invaluable labor de definir los contornos de esos derechos y garantías mediante la aplicación directa de la Constitución y los tratados internacionales en materia de derechos humanos.

Sin embargo, esta trascendente labor se havisto devaluada por pronunciamientos del mismo Tribunal acuñados al examinar la satisfacción de los requisitos de admisibilidad y procedencia de la mencionada causal de invalidación, mediante interpretaciones que restringen injustificadamente el derecho al recurso, conforme al cual, según la jurisprudencia de la Corte Interamericana de Derechos Humanos y la doctrina, este medio de impugnación debiera ser accesible con mínimas formalidades para su admisión y eficaz, interpretándose sus normas reguladoras del modo más favorable a su admisión y sustanciación.

Las limitaciones al derecho al recurso, en particular al recurso de nulidad por la causal de la letra a) del artículo 373 del CPP, derivan de las siguientes causas que a continuación se enumeran y sintetizan:

1) Limitaciones derivadas de la autorrestricción de su competencia al reconducir la Corte los hechos de la causal de la letra a) del artículo 373 del CPP a alguno de los motivos absolutos de nulidad del artículo 374 del CPP como autoriza el artículo 383, inciso $3^{\circ}$, letra a), del CPP, lo que se ejecuta con vasta discrecionalidad sin, por tanto, apegarse a directrices definidas, amparada en la amplitud de los términos de los motivos de invalidación a que redirige.
2) Limitaciones por medio de sumar requisitos sujetos a los controles de admisibilidad previstos en los artículos 380 y 383 del CPP, como exigir el señalamiento expreso de la sustancialidad de la infracción y de la forma --conjunta o subsidiariamente- en que se interponen las causales de las letra a) y b) del artículo 373 del CPP, y objetar la formulación de peticiones no congruentes con la causal propuesta, demandas que, aunque resultan válidas para la adecuada tramitación, conocimiento y decisión del recurso, pueden salvarse otorgando un plazo acotado al recurrente para enmendar tales defectos sin privarlo del ejercicio del derecho al recurso.

3) Limitaciones por la vía de adelantar un pronunciamiento sobre el fondo de la controversia planteada en el recurso al examen de admisibilidad.

4) Limitaciones procedentes de la interposición conjunta de causales incompatibles, defecto este último que no debiera estorbar para pronunciarse al menos respecto de la causal de competencia natural de la Corte, con el objeto de no dejar una eventual infracción de derechos fundamentales sin sanción procesal.

5) Limitaciones consistentes en declarar ciertas materias extrañas al recurso de nulidad, como la revisión del desempeño del defensor en las audiencias de preparación del juicio oral y juicio oral, la no suspensión del procedimiento de conformidad con el artículo 458 del CPP, y la infracción de garantías fundamentales cometidas en la interpretación del contenido de un tipo penal, lo que importa excluir de manera general ciertas materias como objeto de su conocimiento, incluso en sede de admisibilidad, con lo cual no solamente cercena su competencia por vía interpretativa, sino que priva absolutamente al recurrente de la posibilidad de demostrar en el caso particular la existencia de la infracción. 
6) Limitaciones por la vía de restringir la legitimidad para deducir el recurso, al declarar que puede interponerse únicamente por el afectado directamente por la infracción de garantías, y que el fiscal y el querellante no pueden ser sujetos pasivos de ésta, supeditando en el primer caso la admisibilidad y procedencia del arbitrio a razonamientos propios del ámbito comparado que no se acomodan a nuestro ordenamiento procesal y, en el segundo, oponiéndose al texto expreso de la ley en lo referido al derecho del ofendido a impugnar la sentencia absolutoria.

7) Limitaciones por el condicionamiento de la suerte del recurso basado en la letra a) del artículo 373 a la interposición de la causal de la letra e) del artículo 374, cuando quien recurre disiente del relato fáctico establecido por el tribunal de juicio sobre la forma en que se habría obtenido la prueba, condición que no permite solucionar esta problemática, pareciendo únicamente efectiva su formulación para, en un segundo juicio, conseguir la declaración de ilicitud.

8) Limitaciones que son consecuencia de dirimir si se presentan los extremos de sustancialidad de la infracción e influencia en lo dispositivo del fallo impugnado, según si la prueba rendida en el juicio que no proviene de aquella actuación que el impugnante tacha de ilegal, resultaba o no igualmente suficiente para arribar a la decisión condenatoria, lo que supone necesariamente sustituir el lugar de los jueces de la instancia en la valoración de la prueba rendida en el juicio, lo que se efectúa, además, mediante soluciones de corte aritmético.

\section{Referencias}

Accatino Scagliotti, D. (2009). Forma y sustancia en el razonamiento probatorio: El alcance del control sobre la valoración de la prueba a través del recurso de nulidad. Revista de Derecho de la Pontificia Universidad Católica de Valparaíso, (32), 347-362.

Aldunate, E. (2008). Derechos fundamentales. Santiago: LegalPublishing.

Awad, A., Contreras, M. y Schürmann, M. (2013). Procesal Penal. Revista de Derecho de la Universidad Adolfo Ibáñez, (3), 381-429.

Blanco Suárez, R. (2011). Código Procesal Penal. Santiago: Legal Publishing.

Carocca Pérez, A. (2009). Manual el nuevo sistema procesal penal (5a ed.). Santiago: Legal Publishing.

Cerda San Martín, R. (2010). Manual del Sistema de Justicia Penal. T. II. (2ª ed.). Santiago: Librotecnia.

Cortés-Monroy Fernández, J. (2018). La "valoración negativa" como exclusión de la prueba ilícita en el juicio oral. Revista lus et Praxis, 24(1), 661-692.

Cortez Matcovich, G. (2006). El recurso de nulidad: Doctrina y Jurisprudencia (2a ed.). Santiago: Legal Publishing.

Chahuán Sarrás, S. (2009). Manual del nuevo procedimiento penal (6ª ed.). Santiago: Legal Publishing.

Del Río Ferretti, C. (2012). Estudio sobre el derecho al recurso en el proceso penal. Centro de Estudios Constitucionales de Chile Universidad de Talca, 10(1), 245-288.

Del Río Ferretti, C. (2014). El derecho al recurso y recurso de nulidad penal. Santiago: Legal Publishing.

Duce Julio, M. y Riego Ramírez, C. (2007). Proceso Penal. Santiago: Editorial Jurídica de Chile.

Hernández Basualto, H. (2005). La exclusión de la Prueba llícita en el Nuevo Proceso Penal Chileno. Santiago: Universidad Alberto Hurtado.

Horvitz Lennon, M.I. y López Masle, J. (2008). Derecho Procesal Penal Chileno, T. II. Santiago: Editorial Jurídica de Chile. Jiménez Contreras, P. (2003). De los recursos: Proceso Penal Acusatorio. Santiago: Metropolitana.

Maier, J. (2004). Derecho Procesal Penal. T. I. (2 ed.). Buenos Aires: Editores del Puerto. 
Moreno Holman, L. (2013). El modelo adversarial en Chile: Ponencias sobre su implementación en la reforma procesal penal. Santiago: Legal Publishing.

Mosquera Ruiz, M. y Maturana Miquel, C. (2010). Los Recursos Procesales. Santiago: Editorial Jurídica de Chile.

Núñez Ojeda, R. (2012). Código Procesal Penal. Santiago: Legal Publishing.

Núñez Vásquez, C. (2003). Tratado del proceso penal y del juicio oral. T. II. Santiago: Editorial Jurídica de Chile.

Núñez, R., Beltrán, R. y Santander, N. (2019). Los hallazgos casuales en las diligencias de incautación e intervención de las comunicaciones digitales en Chile. Algunos problemas. Política Criminal, 14(28), 152-185.

Orellana Torres, F. (2010). Manual de Derecho Procesal. T. V. (2a ed.). Santiago: Librotecnia.

Palomo, D. y Lorca, N. (2018). Sistema recursivo en los modelos reformados de la Justicia chilena: ¿Un avance o un retroceso? En D. Palomo (Dir.). Justicia y proceso (pp. 25 - 87). Santiago: DER.

Pfeffer Urquiaga, E. (2010). Código Procesal Penal (2ª ed.). Santiago: Editorial Jurídica de Chile.

Riego Ramírez, C. (2007). El recurso de nulidad en el nuevo sistema procesal. En A. Romero (Coord.). Estudios de derecho en homenaje a Raúl Tavolari Oliveros (pp. 429-443). Santiago: LexisNexis.

Rieutord Alvarado, A. (2007). El recurso de nulidad en el nuevo proceso penal. Santiago: Editorial Jurídica.

Rodríguez Vega, M. (2020). Diligencias investigativas por infracciones a la Ley N 20.000 y debido proceso. Santiago:

Rubicón Editores.

Romero Muza, R. (2007). Control de Identidad y Detención (2 ed.). Santiago: Librotecnia.

Sandaña Jeno, L. (2010). Recursos en el Código Procesal Penal. En Apuntes de Derecho Procesal Penal. El Ministerio Público y el proceso penal oral (pp. 219-236) (8 ed.). Santiago: Legal Publishing.

Tavolari Oliveros, R. (2003). Informe en derecho: del debate sobre la licitud de la prueba y su exclusión por parte del tribunal de juicio oral y procedencia legal de consignar en la sentencia de juicio oral las decisiones relevantes adoptadas en la audiencia. Boletín del Ministerio Público, (14), 151-160.

Tavolari Oliveros, R. (2005). Instituciones del nuevo Proceso Penal. Santiago: Editorial Jurídica de Chile.

Zapata García, M. F. (2004). La prueba ilícita. Santiago: Lexis Nexis.

\section{Jurisprudencia}

Ministerio Público contra Yanina Furlong (2010) Corte Suprema, 25 de mayo de 2010, Rol № 1741-2010 Ministerio Público contra Paulina González (2015) Corte Suprema, 4 de junio de 2015, Rol № 4.949-2015 Ministerio Público contra Constanzo Ruz (2016) Corte Suprema, 23 de mayo de 2016, Rol № 21.430-2016 Ministerio Público contra Lizama Rodríguez (2016) Corte Suprema, 22 de noviembre de 2016, Rol № 73.836-2016 Ministerio Público contra Martin Vukoicic (2017) Corte Suprema, 21 de febrero de 2017, Rol № 100.710-2016 Ministerio Público contra Vilches Arena (2017) Corte Suprema, 20 de abril de 2017, Rol № 39.475-2016 Ministerio Público contra Núñez Castillo (2017) Corte Suprema, 24 de julio de 2017, Rol N²4.860-2017 Ministerio Público contra Becerra Ulloa (2018) Corte Suprema, 8 de enero de 2018, Rol № 42.684-2017 Ministerio Público contra Trujillo Flores (2018) Corte Suprema, 7 de marzo de 2018, Rol N 1.127-2018 Ministerio Público contra Herrera Carilao (2018) Corte Suprema, 26 marzo 2018, Rol № 2.519-2018 Ministerio Público contra Carvajal Bonilla (2018) Corte Suprema, 10 de octubre de 2018, Rol N²0.749-2018 Ministerio Público contra Miranda Ponce (2018) Corte Suprema, 6 de diciembre de 2018, Rol N 26.422-2018 Ministerio Público contra De la Fuente Henríquez (2019) Corte Suprema, 7 de marzo de 2019, Rol № 2.224-2019 
Ministerio Público contra Pacheco Ruminot (2019) Corte Suprema, 3 de junio de 2019, Rol No 9.140-2019 Ministerio Público contra González Rincón (2019) Corte Suprema, 26 de junio de 2019, Rol № 12.166-2019 Ministerio Público contra Cifuentes Larios (2019) Corte Suprema, 2 de julio de 2019, Rol № 12.003-2019 Ministerio Público contra Sanhueza Laurie (2019) Corte Suprema, 30 de septiembre de 2019, Rol № 23.136-2019 Ministerio Público contra Fernando Palacios (2019) Corte Suprema, 22 de octubre de 2019, Rol № 29.124-2019 Ministerio Público contra Bustamante Opazo (2019) Corte Suprema, 28 de octubre de 2019, Rol № 21.413-2019 Ministerio Público contra Carvajal Guerrero (2019) Corte Suprema, 11 de noviembre de 2019, Rol № 27.768-2019 Constructora Inversiones Fenaez Ltda. contra Elizabeth López (2019) Corte 19 de diciembre de 2019, Rol № 36.495-2019 Ministerio Público contra González Muñoz (2019) Corte Suprema, 23 de diciembre de 2019, Rol № 29.032-2019 Ministerio Público contra Luis Alvarado (2019) Corte Suprema, 23 de diciembre de 2019, Rol № 36.736-2019 Ministerio Público contra Esteban Luna (2020) Corte Suprema, 8 de enero de 2020, Rol № 40.950-2019 Ministerio Público contra Roberto Chávez (2020) Corte Suprema, 8 de enero de 2020, Rol № 41.140-2919 Ministerio Público contra Brians Rojas (2020) Corte Suprema, 22 de enero de 2020, Rol № 29.160-2019 Ministerio Público contra Jorge Altamirano (2020) Corte Suprema, 27 de enero de 2020, Rol № 33.699-2019 Ministerio Público contra López Ampuero (2020) Corte Suprema, 31 de enero de 2020, Rol № 250-20 Ministerio Público contra Olave Torres (2020) Corte Suprema, 31 de enero de 2020, Rol N 1.561-20 Ministerio Público contra Jorge López (2020) Corte Suprema, 4 de febrero de 2020, el Rol № 2.892-2020. Ministerio Público contra Juan Ugarte (2020) Corte Suprema, 11 de febrero de 2020, Rol N².894-2020 Ministerio Público contra Isabel Millán (2020) Corte Suprema, 11 de febrero de 2020, Rol № 7.893-2020 Ministerio Público contra Matías González (2020) Corte Suprema, 11 de febrero de 2020, Rol № 14.768-2020 Ministerio Público contra Ignacio Correa (2020) Corte Suprema, 12 de febrero de 2020, Rol № 132.331-2020 Ministerio Público contra Edgardo Seisdedos (2020) Corte Suprema, 14 de febrero de 2020, Rol № 15.033-2020 María Seguel contra Gisela Faúndez (2020) Corte Suprema, 17 de febrero de 2020, Rol No 15.031-2020 Solange de Vidts contra Leonardo León (2020) Corte Suprema, 27 de febrero de 2020, Rol № 26.890-2019 Ministerio Público contra Víctor Jofré (2020) Corte Suprema, 3 de marzo de 2020, Rol № 20.925-2020 Ministerio Público contra Ermes Pequi (2020) Corte Suprema, 13 de marzo de 2020, Rol № 14.733-2020 Ministerio Público contra Martínez Escobar (2020) Corte Suprema, 17 de marzo de 2020, Rol № 24.696-2020 Jaime Isla contra Moisés Jeldrez (2020) Corte Suprema, 19 de marzo de 2020, Rol № 15.028-2020 Ministerio Público contra Krishna Araya (2020) Corte Suprema, 25 de marzo de 2020, Rol № 30.473-2020 Ministerio Público contra Camilo Barrera (2020) Corte Suprema, 26 de marzo de 2020, Rol № 14.773-2020 Ministerio Público contra Pablo Ortiz (2020) Corte Suprema, 8 de abril de 2020, Rol № 30.154-2020 Ministerio Público contra Alexis González (2020) Corte Suprema, 9 de abril de 2020, Rol No 33.124-2020 Ministerio Público contra Queipul Hueiquil (2020) Corte Suprema, 9 de abril de 2020, Rol №30.166-20 Ministerio Público contra Ignacio Olmedo (2020) Corte Suprema, 14 de abril de 2020, Rol №33.343-2020 Intendencia de la Araucanía contra Daniel Canio (2020) Corte Suprema, 16 de abril de 2020, Rol No 14.771-2020 Fegal Limitada contra Víctor Gallardo (2020) Corte Suprema, 30 de abril de 2020, Rol № 42.778-2020 Ministerio Público contra Gabriela Llantén (2020) Corte Suprema, 30 de abril de 2020, Rol № 42.873-2020 Ministerio Público contra Nicolás Salvo (2020) Corte Suprema, 30 de abril de 2020, Rol № 42.804-2020 Ministerio Público contra Felipe Vega (2020) Corte Suprema, 29 de mayo de 2020, Rol № 42.776-2020 Ministerio Público contra Hernán Farías (2020) Corte Suprema, 9 de junio de 2020, Rol № 62.816-2020 Ministerio Público contra Jimmy Madrid (2020) Corte Suprema, 14 de julio de 2020, Rol № 78.852-2020 Ana Ferrada contra Joel Durán (2020) Corte Suprema, 1 de septiembre de 2020, Rol № 95.056-2020 Ministerio Público contra Daniel González (2020) Corte Suprema, 1 de septiembre de 2020, Rol No 97.367-2020 Ministerio Público contra Jorge Sumarett (2020) Corte Suprema, 1 de septiembre de 2020, Rol N 97.243-2020 
Ministerio Público contra Jonathan Torregroza (2020) Corte Suprema, 11 de septiembre de 2020, Rol N 90.633-2020 Ministerio Público contra Marcos Cáceres (2020) Corte Suprema, 16 de septiembre de 2020, Rol № 104.174-2020 Ministerio Público contra Guillermo Ibarra (2020) Corte Suprema, 16 de septiembre de 2020, Rol № 104.407-2020 Ministerio Público contra Iván Morovic (2020) Corte Suprema, 7 de octubre de 2020, Rol № 97.242-2020 Ministerio Público contra Josué Ávila (2020) Corte Suprema, 20 de octubre de 2020, Rol № 124.395-2020 Ministerio Público contra Jhonny Agudelo (2020) Corte Suprema, 20 de octubre de 2020, Rol No 122.149-2020 Guillermo Espinosa contra Renzo Hormazábal (2020) Corte Suprema, 23 de octubre de 2020, Rol No 112.393-2020 Ministerio Público contra José Ortiz (2020) Corte Suprema, 25 de noviembre de 2020, Rol N 134.015-2020 Ministerio Público contra Hugo Cid (2020) Corte Suprema, 15 de diciembre de 2020, Rol No 139.997-2020 Angélica Paredes contra Felipe Santana (2020) Corte Suprema, 15 de diciembre de 2020, Rol No 138.481-2020 Sandra Losada contra Raúl Rojas (2020) Corte Suprema, 8 de abril de 2021, Rol № 14.317-2021 Pablo Cariola contra Guangyi Chen (2020) Corte Suprema, 16 de junio de 2021, Rol No 17.299-2021 Ministerio Público contra Gustavo Allende (2020) Corte Suprema, 25 de junio de 2021, Rol № 25.386-2021 